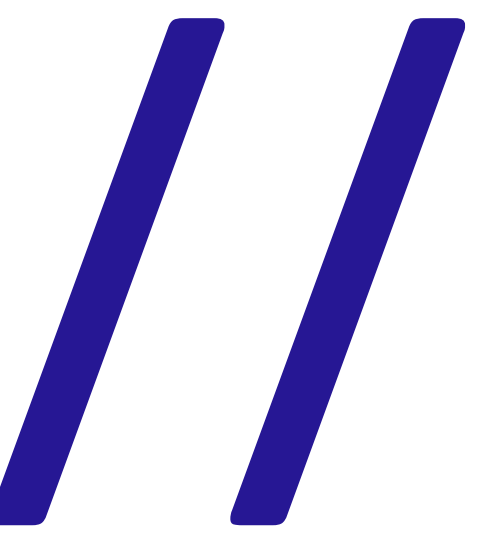

\title{
Kleber Mendonça e a ciranda de todos nós:
} configurações espaciais e resistência Kleber Mendonça and everybody's "ciranda": spatial configurations and resistance

Genilda Azerêdo ${ }^{1}$

\footnotetext{
${ }^{1}$ Possui graduação em licenciatura plena em Letras (1985), especialização em Literatura Anglo-Americana (1986) e mestrado em Letras (1990) pela Universidade Federal da Paraíba (UFPB) e doutorado em Letras: Inglês e Literaturas de Língua Inglesa (2001) e pós-doutorado (2018) pela Universidade Federal de Santa Catarina (UFSC). Atualmente é professora titular da UFPB e é pesquisadora-bolsista PQ2/CNPq desde 2009. Tem experiência na área de Letras, com ênfase em Literaturas Estrangeiras Modernas, atuando principalmente nas seguintes áreas: cinema e literatura; adaptação fílmica; teorias da narrativa literária e fílmica; narrativas poéticas. E-mail: genildaazeredo@yahoo.com.br
} 
Resumo: A questão espacial é uma preocupação nos filmes do diretor Kleber Mendonça Filho, sendo uma problemática significativa em Recife frio, $\mathrm{O}$ som ao redor $\mathrm{e}$ Aquarius, algo indiciado nos próprios títulos. Partimos da premissa de que os conflitos vivenciados pelos personagens são indissociáveis dos espaços que habitam e por onde (não) circulam. Nesses filmes, as configurações espaciais refletem relações de força e hierarquias de classe que, por sua vez, denotam resistência e violência. Dada a multiplicidade de sentidos que os diferentes espaços produzem, a discussão é embasada em Bachelard, Foucault, Soja e Ryan, Foote e Azaryahu, teóricos que investigam, respectivamente, a relação entre sensorialidade e espaço; espaço e relações de poder; narrativa; e geografia. A análise demonstra a relevância de Recife frio para uma compreensão dos outros filmes, como se constituíssem, no que diz respeito ao espaço, prismas de um mesmo objeto.

Palavras-chave: narrativa; espaço; resistência; Kleber Mendonça.

Abstract: The issue of space is a major concern in Kleber Mendonça Filho's filmography, being a significant problematic in Recife frio, $\mathrm{O}$ som ao redor and Aquarius, an aspect already suggested in the titles. The premise is that the conflicts which the characters experience are intimately associated with the spaces they inhabit and where they (do not) circulate. In these films, spatial configurations reflect power relations and class hierarchies, which, in turn, denote resistance and violence. Considering the multiple meanings the different spaces produce, we support our discussion in Bachelard, Foucault, Soja and Ryan, Foote and Azaryahu, theoreticians who respectively investigate 
the relation between the sensorial and space; space and relations of power; narrative; and geography. The analysis reveals the relevance of Recife frio for an understanding of the other films, as if they constituted, concerning space, prisms of the same object. Keywords: narrative; space; resistance; Kleber Mendonça.

\section{Introdução: espaço, poder e produção social}

Todos sabemos da relevância do espaço como categoria narrativa nas diversas expressões artísticas (literárias, fílmicas, intermidiáticas). Em determinados autores, diretores e correntes, o espaço é tão vívido que chega mesmo a se confundir com a ação dos personagens, como se também tivesse alma e vontade própria. Tal é o caso da configuração espacial no conto "The fall of the house of Usher", de Edgar Allan Poe - em que Usher tanto significa o sobrenome da família quanto, por metonímia, o nome da casa; ao criar uma relação especular entre "house" e "Usher" (termos contendo quase as mesmas letras), Poe sugere falta de limite entre a família e a casa que a abriga. Outro exemplo significativo é o romance The house of mirth, de Edith Wharton, que representa a trajetória de Lily Bart, personagem sem-teto, solta no mundo, cuja densidade psicológica é construída, sobretudo, através dos espaços transitórios que habita, da busca incessante por uma casa e pela possibilidade de formar uma família e enfim criar raízes.

Em narrativas fílmicas, dada a relevância da imagem no cinema, o espaço parece se confundir com a própria materialidade cinematográfica, sendo a tela, onde (quase) tudo acontece, um limite, índice espacial que mostra do panorâmico ao minúsculo, do visível ao entrecortado ou desfocado, do preto e branco ao desbotado ou colorido. Ou seja, o cinema é uma expressão artística em que o espaço - seja o que é mostrado na tela, seja o que tal visibilidade sugere ou exclui - constitui função preponderante. De fato, nunca podemos esquecer "desse espaço invisível, mas prolongando o visível, que se chama fora de campo" (AUMONT, 1995, p. 24). Em filmes que tematizam a questão espacial - chamando atenção para a arquitetura e paisagens urbanas -, há um adensamento da configuração espacial, quase como se houvesse uma redundância em sua representação.

O espaço é uma preocupação central nos filmes do diretor Kleber Mendonça Filho, sendo uma problemática significativa em Recife frio (2009), O som ao redor (2013) e Aquarius (2016), algo já sugerido nos próprios títulos. A propósito, o curta Recife frio faz referência a um livro do arquiteto pernambucano Armando de Holanda, intitulado Roteiro para construir no Nordeste: arquitetura como lugar ameno nos trópicos ensolarados, destinado, segundo a voz narrativa, a "construções 
humanas e generosas", ou seja, "a uma poesia impossível". A referência aparece em um contexto que denuncia o aumento vertiginoso dos prédios e de uma arquitetura e paisagem urbana que segregam e desumanizam. Nele, a tonalidade utilizada é irônica e paródica, diferente daquela adotada nos dois outros filmes. A despeito dessa diferença, lançamos a hipótese de que Recife frio antecipa, de modo embrionário, várias problemáticas desenvolvidas nos filmes posteriores, a exemplo do conflito de classes, do drama social, dos efeitos advindos da especulação imobiliária e da desumanização resultante do (des)ordenamento das cidades.

Partindo dessas considerações iniciais, propomos a discussão dos três filmes tendo como foco a questão espacial com a cidade do Recife, captada entre a fantasia distópica de Recife frio e as conotações realistas de $\mathrm{O}$ som ao redor e Aquarius. Algumas das questões que motivam a presente discussão são: De que modo a configuração espacial contribui para os significados da narrativa fílmica como um todo? Que efeitos a tonalidade irônica de Recife frio provoca quando pensamos no "Recife" dos outros filmes? Como as narrativas articulam os espaços com a crítica social e os diferentes gêneros (documental, suspense, thriller) que informam os filmes? Que gestos de resistência os espaços indiciam? Também lançamos a hipótese, como trajetória de investigação, de que os três filmes aqui abordados configuram espaços que vão desde a cidade (Recife frio), o bairro, a rua (O som ao redor), até culminar na interioridade do edifício e da casa (Aquarius). É relevante ressaltar que a sequência final de $\mathrm{O}$ som ao redor, em que a violência irrompe no interior do apartamento, com a sugestão de assassinato - deslocando-se, portanto, da rua para o interior da casa já antecipa a ênfase dada à relação entre espaço doméstico e violência em Aquarius.

O conceito que Ryan, Foote e Azaryahu (2016, p. 24)² oferece em Narrating space/spatializing narrative, para spatial frames (molduras espaciais) nos será bastante funcional nesta articulação. Segundo os autores:

Como o termo 'moldura' sugere, molduras espaciais são repletas de coisas individuais e se definem pelo conjunto de objetos que contêm. [...] Molduras espaciais são hierarquicamente organizadas pelas relações de contenção (um quarto ou sala como subespaço de uma casa) e seus limites podem ser demarcados ou indefinidos (por exemplo, uma paisagem pode gradativamente mudar à medida que os personagens se movem através dela).

\footnotetext{
${ }^{2}$ Embora o livro tenha autoria plural, cada autor foi responsável por capítulos específicos. O trecho citado é do segundo capítulo, de autoria de Ryan. As traduções de trechos em inglês são da autora deste texto.
} 
Quando pensamos nesses três filmes do cineasta, o conceito de "molduras espaciais" ascende em significância, seja para revelar a organização hierárquica entre os diferentes compartimentos de uma casa (Recife frio); as fronteiras sociais e econômicas entre diferentes bairros e ruas de uma cidade (O som ao redor; Aquarius); ou mesmo o confinamento de um apartamento em relação aos demais de um prédio (Aquarius). Nos três filmes aqui discutidos, temos referências explícitas não apenas aos espaços em termos arquitetônicos (a casa grande, as ruínas de um cinema e de um engenho de cana de açúcar em $\mathrm{O}$ som ao redor; o quarto de empregadas como um recinto quente em Recife frio e O som ao redor; os arranha-céus e condomínios fechados da cidade nos três filmes), mas também à relação entre arquitetura e especulação imobiliária ou, mais especificamente, às forças que regem os diferentes espaços - seja, como antecipamos, em uma cidade (Recife frio), uma rua (O som ao redor) ou um prédio (Aquarius).

Marie-Laure Ryan, Kenneth Foote e Maoz Azaryahu (2016, p. 1) também argumentam que o espaço serve a várias funções narrativas, "podendo ser um foco de atenção, um condutor de significado simbólico, um objeto de investimento emocional, uma forma de planejamento estratégico, um princípio de organização e até uma mídia que serve de suporte para a narrativa". Ao abordarem a questão espacial em articulação com a geografia - o subtítulo do livro Narrating space/spatializing narrative é where narrative theory and geography meet (onde a teoria narrativa e a geografia se encontram) -, os autores propõem uma aproximação entre narratologia e geografia, de modo a aprofundar uma compreensão da experiência espacial humana em articulação com uma maior percepção de formas e teorias narrativas (RYAN; FOOTE; AZARYAHU, 2016, p. 1).

Tentando especificar ainda mais tais relações, não é à toa que os espaços, nos filmes de Kleber Mendonça Filho, quase sempre potencializam um drama humano e social, ora conotando os sujeitos como se encurralados em corredores e entre grades ver, por exemplo, o casal de adolescentes se beijando escondido ou crianças tentando brincar de bola em $\mathrm{O}$ som ao redor -, ora dando a ver uma liberdade ilusória por exemplo, quando personagens se "refugiam" no topo de edifícios e observam a cidade lá de cima. A quantidade de grades nos condomínios é tamanha, que produz uma semelhança entre casas e prisões, e, embora as crianças ainda tentem brincar na rua, trata-se de uma tentativa fracassada, como mostra a bola destruída por um carro.

De fato, a configuração espacial é tão relevante nesses filmes que os sujeitos são apreendidos em suas relações com tais espaços, numa clara referência àquilo que Edward Soja (1993, p. 136) denomina "espacialidade da vida social”, princípio que considera o mundo e a vida como situados (sitiados) não apenas em contextos 
históricos, mas também em geografias humanas, possibilitando uma consciência sobre "a produção social do espaço". Isso serve tanto para aquele que se coloca como dono de uma rua (portanto, alguém que conseguiu materializar o sonho do eu-lírico na canção "Se essa rua, se essa rua fosse minha...") quanto para aquele destituído de tal autoridade, que precisa pedir licença para adentrar tal território. Nas palavras de Foucault, "vivemos em um conjunto de relações que delineia lugares irredutíveis em relação a outros lugares; lugares que, de modo algum, podem ser sobrepostos a outros lugares" (1986, p. 23 apud SOJA, 1993, p. 142), como se a compartimentalização, o distanciamento e a separação fossem a tônica.

Vejamos inicialmente dois exemplos: em $\mathrm{O}$ som ao redor, Dinho repete aos "seguranças" o discurso do avô a respeito de quem é o dono da rua: "essa rua é da minha família; isso aqui não é favela, não é rua de pobre”. A rua, portanto, é definida não apenas pelo que é, mas, principalmente, pelo que não é, por aquilo (e aqueles) que exclui. Embora os "seguranças" (leia-se, milícia) tenham delimitado, com uma tenda, seu território no espaço da rua, tanto avô quanto neto deixam claro que eles só estão ali porque o "dono" da rua permitiu. Outro exemplo diz respeito à mãe que subverte as funções dos eletrodomésticos (seja para fumar maconha, seja para se masturbar), de modo a transformar a casa em espaço peculiarmente seu (ver o curta Eletrodoméstica (2005), do diretor, em que a relação entre sujeito, espaço doméstico e máquina é desenvolvida). Sua vida de mãe e dona de casa é tão solitária, angustiante e esvaziada de sentido que, por um breve momento, ela espia os filhos na aula de chinês, talvez com certa inveja - mas, até nesse caso, sua permanência ali é interditada, já que, segundo a professora, sua presença está distraindo a atenção dos alunos. Com efeito, Bia se sente deslocada em sua própria casa.

Também é interessante ressaltar o jogo sinestésico e metonímico construído através da justaposição entre sonoridade e espaço, perceptíveis no título $O$ som ao redor. Os ruídos são inicialmente domésticos, ou do cotidiano da rua, de fogos de artifício, mas logo o espectador percebe um perigo que paira nos silêncios e nas pausas. A esse propósito, ressaltemos a criatividade da montagem, no final do filme, quando o som de bombas de artifício se confunde com tiros, em uma irônica sobreposição de ludicidade e violência. Observemos também a sequência de abertura do filme, com planos de fotografia em preto e branco, que introduzem outro tempo e outros espaços - aqueles dos engenhos, dos trabalhadores escravizados e oprimidos pelo patrão e pelo capataz. Ironicamente, trata-se de um prólogo eloquente que metaforiza os espaços seguintes (agora urbanos), como se o tempo não tivesse passado; como se a mesma autoridade do senhor de engenho tivesse apenas se deslocado para o espaço urbano burguês. 
Em texto intitulado "Espaço, poder e conhecimento", sobre a relevância da arquitetura e do espaço, Foucault (1993, p. 168) afirma a centralidade do espaço em todo tipo de vida comum e diz que "o espaço é fundamental em todo exercício de poder". Como consequência, ele vê a arquitetura não apenas como "alocação de pessoas em um determinado espaço, canalização de sua circulação, codificação de suas relações recíprocas", mas também como "um mergulho em um campo de relações sociais que provoca efeitos específicos” (FOUCAULT, 1993, p. 169, grifo do autor). Continuemos, a seguir, a pensar em alguns desses efeitos, tomando como base Aquarius.

\section{Espaço e resistência em Aquarius}

Todas essas tensões advindas da relação entre sujeito e espaço constituem a questão fundamental em Aquarius, filme mais recente de Kleber Mendonça. Clara, a protagonista (vivida por Sônia Braga no segundo momento do filme, o estágio diegético presente), quer apenas isto: o direito de morar em sua casa, de viver ali até morrer. Casa e vida são a mesma coisa para ela - minha casa, minha vida. Aquarius (atente-se para a polissemia do termo: “aquário" denota limite e confinamento) é o nome do prédio onde Clara vive, em Boa Viagem, Recife. Ela é a única habitante do edifício; todos os outros moradores já venderam seus apartamentos e se mudaram. As forças com as quais Clara tem que lutar são as das construtoras e da especulação imobiliária - a potência do capital e de tudo que o dinheiro pode aparentemente comprar -, as quais lhe declaram uma sórdida e explícita guerra. Mas há uma gradação nesse jogo de forças, inicialmente conotado pelo vai e vem do envelope da construtora por baixo da porta, quando da tentativa de convencer Clara a ouvir a proposta dos empresários. Um jogo para medir quem pode mais.

Assim como O som ao redor - composto a partir de três blocos narrativos ("Cães de guarda"; "Guardas noturnos" e "Guarda-costas") - Aquarius divide-se em três partes (Parte I: "O cabelo de Clara”; Parte II: "O amor de Clara”; Parte III: "O câncer de Clara”). Se os títulos naquele aludem à questão de (falta de) segurança, (des)proteção e, por contiguidade, violência, e a diferentes modos de enfrentá-la, neste, referem-se a uma única personagem, em diferentes fases de sua vida, também permeada pela violência. A primeira parte evoca o momento quando Clara enfrentou um câncer de mama e precisou fazer uma cirurgia para retirá-la. Aqui, anos 1980, ela tem cabelos curtinhos, ao modo de Elis Regina. Toda essa primeira parte contextualiza a família de Clara, em que estão presentes filhos pequenos, marido, familiares e Tia Lúcia, cujo aniversário eles estão celebrando. 
A segunda parte do filme, "O amor de Clara", embora situada na mesma casa, no mesmo apartamento, é cronologicamente fincada em outro tempo. Clara, agora viúva, mora sozinha, os filhos estão crescidos, adultos, e Clara já é avó. É interessante registrar, nessa transição entre as duas temporalidades, a presença de um móvel, um armário, guardador de objetos e de tempos, que faz a conexão entre o ontem e o hoje de Clara; também de toda a coleção de discos, livros, quadros e outros objetos que povoam a casa. Lembremos que essa relação afetiva com a casa, embora com menos ênfase, também se encontra em $O$ som ao redor, por meio da personagem Sofia. Em Aquarius, claramente observamos a função simbólica dos objetos, que encharcam o espaço de modo a transformá-lo naquilo que Ryan, Foote e Azaryahu (2016, p. 39) denominam "espaço emocional": "Na relação emocional [com o espaço] objetos espaciais importam pelas experiências que comportam, pelos sentimentos estéticos que inspiram e pelas memórias que trazem à mente".

A casa (aparentemente) é a mesma. O amor de Clara pela casa também é o mesmo. Lembremo-nos de Bachelard (1974, p. 358) quando diz que "todo espaço verdadeiramente habitado traz a essência da noção de casa”; e ainda, que "o ser abrigado sensibiliza os limites de seu abrigo". Clara e a casa são indissociáveis. "O amor de Clara", que intitula essa parte, tanto se refere à família, aos filhos, ao amor ausente-presente, à vida vivida, quanto à casa que tudo guarda - casa-arquivo, casa-memória. A dedicatória aos filhos, em um dos livros escritos por Clara, ilustra bem a articulação entre ausência e presença, através da memória. Como no poema de Carlos Drummond de Andrade (1980, p. 169-170): "Mas as coisas findas/muito mais que lindas/essas ficarão".

A terceira parte, intitulada "O câncer de Clara", ressalta, de modo eloquente, as estratégias sórdidas utilizadas pela construtora para forçá-la a deixar seu apartamento. Festas-orgias são dadas em apartamento acima do seu, com música não apenas de péssima qualidade, mas em volume altíssimo, impedindo-a de dormir; sujeira é espalhada pela escadaria; colchões são queimados na área comum do prédio; cultos são realizados. "Você não me conhece, Clara", é o aviso-ameaça que o empresário, dono da construtora, dispara. E tudo culmina com a descoberta dos cupins, plantados de modo proposital em dois apartamentos, para que o edifício enfim sucumba e desmorone. Já que Clara não arreda pé, eis a solução encontrada! "O câncer de Clara" - antes de mama - agora se refere aos cupins que ameaçam sua casa-vida, um deslocamento metafórico que diz da agressividade, do poder de destruição dos cupins, bem como do efeito disso sobre Clara - um "câncer" que ela prefere dar a de novo vivenciar. 
Em texto intitulado "Clara e a resistência", Ângela Prysthon (2016, p. 71) chama a atenção para uma marca significativa da filmografia de Kleber Mendonça: "tentativa de ruptura com certo padrão de caracterização regional que tenderia ao folclórico e ao caricatural [...]; seus filmes evitam a celebração efusiva dos tipos regionais". Tal escolha se alinha com o fato de os espaços da cidade serem representados nos filmes destituídos de glamour. É interessante perceber que em Recife frio, os repentistas e Lia de Itamaracá poderiam até representar esses tipos regionais, mas o contexto em que aparecem, dada a natureza irônica do filme, acaba por diluir esse dado. A autora também sublinha o fato de que "Aquarius trata exatamente da ideia de resistência, da resiliência de uma mulher contra o apagamento" (PRYSTHON, 2016, p. 71). Não à toa, uma das sequências iniciais do filme, ao captar o espaço geográfico da cidade em câmera alta, também alude às transformações causadas pelo tempo e pela especulação. Se Clara, em termos privados, luta contra o apagamento de sua casa-memória, a perspectiva do filme se alinha com uma crítica mais geral aos danos causados pela especulação imobiliária e consequente destruição do patrimônio arquitetônico.

A sequência final do filme é emblemática da corrupção e podridão entranhadas nos espaços assépticos, habitados pelas famílias e pelos profissionais de modos aparentemente educados e civilizados. Os cupins representam toda a sordidez, todo o desmonte de valores éticos, corretos e justos - uma ilustração do triste momento que temos vivido já há algum tempo no país, em que árvores centenárias são derrubadas e casarões históricos destruídos em nome do lucro das construtoras e empreiteiras. A sequência final dos cupins (destruição) constitui contraponto ao armário (arquivo, memória). Clara resiste. Aquarius resiste. Aquarius, o filme, é exemplo inconteste desta resistência, que talvez apenas a arte possa eloquentemente e substancialmente expressar.

\section{Recife frio, Recife tropical, Recife de (des)encantos mil}

Inicialmente, diria que Recife frio contribui, de forma substancial, para a compreensão da crítica social ligada ao espaço, marcante nos outros filmes. Construído ao modo de uma distopia - em que Recife se constitui como cidade de clima muito frio- e utilizando a ironia como estratégia discursiva principal, esse filme chama a atenção para o drama social dos desvalidos, dos mais pobres - independente do frio. Segundo M. H. Abrams:

o termo distopia ('lugar ruim') tem sido recentemente aplicado a obras de ficção que representam um mundo imaginário muito desagradável, em que tendências agourentas e nefastas 
de ordem tecnológica, política e social do nosso presente são projetadas no futuro. (1988, p. 196)

A frieza aludida no título - sonoramente eloquente em aliteração e assonância - transcende um caráter meramente meteorológico, climático, referencial para conotar a frieza subjetiva e social de um Recife que, através dos espaços, segrega e discrimina. Evidentemente, tal deslocamento é efetuado sobretudo através da duplicidade inerente ao discurso irônico, que amalgama vozes díspares e dissonantes. De fato, a narração de Recife frio é prolífica na inserção não apenas de imagens dentro de imagens (por exemplo, o “papai Noel” se vendo através da TV), mas discursos dentro de discursos (por exemplo, o depoimento do francês dono da pousada).

Não sem razão, toda a preocupação com a questão espacial e com suas ressonâncias socialmente negativas constituem, de modo embrionário, o cerne de Recife frio; tais problemáticas são elaboradas nos filmes posteriores, tendo no desenho, que mostra os compartimentos da casa e chama a atenção para o quarto de empregadas, um exemplo significativo. Por ser o quarto mais quente da casa, agora que Recife é frio, seria supostamente a vez de a empregada usufruir de aconchego natural; mas logo seu quarto é “confiscado", não importando se Recife é quente ou frio, à empregada doméstica sempre caberá a vivência da falta e da opressão (é interessante observar como, na perspectiva da patroa, agora a empregada é um peixe fora d'água, já que esta nunca morou em uma suíte).

A narração em formato de programa científico, ao modo de documentário, também é responsável por criar diversos efeitos irônicos, como, por exemplo, simular caráter de veracidade a uma fantasia distópica. Acrescente-se a este dado o fato de a narração maior ser em espanhol, algo que, além de aprofundar a tonalidade documental (como se outra língua desse maior credibilidade ao discurso), ainda se alinha com o distanciamento necessário em relação à “tragédia” que Recife frio implicaria. A justaposição de imagens de Recife de hoje (frio, cinzento) e Recife de ontem (tropical, carnavalesco, festivo) apenas aparentemente revela uma dissonância. Na profusão de discursos sobre os quais Recife frio se constrói, chamam a atenção notícias dadas em paralelo às previsões do tempo: a demolição do palácio do governo e o fato de pessoas pobres ficarem mais elegantes com roupa de frio. As placas que alertam sobre a violência dos tubarões também permanecem em Recife frio, a despeito de sua inutilidade (pois quem iria tomar banho de mar num frio daqueles?), metonímia que conota uma violência maior, que paira no ar... 
Nesses três filmes, a questão da violência é indissociável dos significados atrelados ao espaço, e o modo como a violência se materializa oscila entre o que é mostrado (arrombamento de carro, tentativa de matar o cachorro, menino agredido violentamente pelos "seguranças", em O som ao redor) e o que é eloquentemente sugerido, tal como o sonho que mostra a invasão da casa por adolescentes pobres. Aquarius também reflete um mundo violento, repleto de ameaças e ações violentas, tanto mais por conta da impunidade e das injustiças. Tal violência, por exemplo, ganha realce quando Clara sonha que a empregada está roubando as joias; quando a empregada diz que seu seio está sangrando, bem como através de momentos de puro suspense: por que é preciso chamar os salva-vidas quando Clara entra no mar? Será apenas pelo perigo das águas, dos tubarões? Ou Clara corre perigo de ser assassinada? Para que os colchões? A sujeira nas escadas é excremento ou sangue? O que vão fazer aqueles homens que seguem Clara, um dos quais, inclusive, bêbado? $\mathrm{O}$ que aqueles homens contaram a Clara? O que os apartamentos escondem? As respostas a essas questões vão sendo dadas paulatinamente, não sem antes criar expectativas e ludibriar o espectador. A narração é feita com estratégias ambíguas, atuações contidas, sutilezas conotativas, aspecto que desestabiliza a aparente narração realista, além de imprimir ao filme uma tonalidade de suspense e medo.

Vistos assim, ainda que superficialmente, Recife frio, $O$ som ao redor e Aquarius reverberam questões importantes da filmografia de Kleber Mendonça Filho: cidade e especulação imobiliária; segregação e espaço; espaço e violência; espaço e resistência. Diria que essas questões são aprofundadas em proporção aos detalhes com que os espaços vão sendo delineados, como se a cidade fosse deslocada de visões panorâmicas ou abertas (Recife frio) para enquadramentos mais específicos da rua, dos prédios e seus entornos (O som ao redor), até chegar à casa (Aquarius). Nesse sentido, trata-se de narrativas que ecoam umas nas outras, como se constituíssem prismas de um mesmo objeto. Por um lado, embora diferentes, as narrativas dos filmes se complementam e informam sobre certa postura autoral de Mendonça Filho. Por outro, as reverberações ilustram também o caráter de incompletude (MILLER, 1995) das narrativas em geral (e dessas, em específico) e dizem também de sua natureza inesgotável, seja quando consideramos quem cria, seja quando consideramos quem aprecia.

A despeito da violência, da discriminação e segregação, existentes em articulação com os espaços, tais filmes esboçam gestos diversos de resistência, cuja materialização mais comovente, na perspectiva do presente trabalho, encontra ressonância metafórica na ciranda de Lia, que, não sem razão, toma o lugar da voz do homem do tempo - voz pragmática e previsível -, abafando-a, anulando-a: 


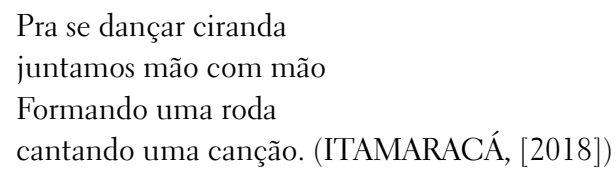

Nos filmes O som ao redor e Aquarius, a solução mais comum para enfrentar a violência, a discriminação e a segregação dá-se sempre por meio de uma saída individual que rompe com o processo civilizatório. Se no final de O som ao redor ainda ressoa a saída coletiva, ao fundir o som dos tiros (vingança individual) ao som dos fogos (gesto coletivo), não há mais lugar para isso em Aquarius: Clara, em nenhum momento, associa o problema do seu apartamento ao problema imobiliário da cidade - seu comportamento despreza os trâmites legais e se assemelha ao gesto do agente imobiliário. Parece que estamos em um mundo anterior ao pacto social, e como o indivíduo não pode contar com o ordenamento jurídico, só lhe resta recorrer à lei da força. Mas em Recife frio, num mundo distópico, uma cena como a da ciranda de Lia tem a força de uma figuração utópica que, certamente, comove o espectador, afetando-o sensorialmente, e, em certo sentido, contaminando o modo como os outros filmes podem também ser apreendidos e vislumbrados.

\section{Referências}

ABRAMS, M. H. A glossary of literary terms. Chicago: Holt, Rinehart and Winston, 1988.

ANDRADE, C. D. de. "Memória”. In: ANDRADE, C. D. de. Antologia poética. Rio de Janeiro: José Olympio, 1980. p 169-170

AUMONT, J. et al. A estética do filme. Tradução de Marina Appenzeller. Campinas: Papirus, 1995.

BACHELARD, G. A poética do espaço. Tradução de Antônio da Costa Leal e Lídia do Valle Santos Leal. São Paulo: Abril Cultural, 1974. (Coleção Os pensadores, v. 38)

FOUCAULT, M. “Space, power and knowledge”. In: DURING, S. (ed.) The cultural studies reader. London: Routledge, 1993.

ITAMARACÁ, L. de. "Minha ciranda”. In: LETRAS. Belo Horizonte: Studio Sol, [2018]. Disponível em: https://bit.ly/2YJxy8U. Acesso em: 6 ago. 2018.

MILLER, J. H. “Narrative”. In: LENTRICCHIA, F.; McLaughlin, T. (ed.). Critical terms for literary studies. Chicago: The University of Chicago Press, 1995. p 66-79. 
PRYSTHON, Â. “Clara e a resistência”. Revista Continente, Recife, v. 188, ano 16, 1 ago. 2016. Disponível em: https://bit.ly/2XHw4dN. Acesso em: 11 jul. 2019.

RYAN, M.-L.; FOOTE, K.; AZARYAHU, M. Narrating space/spatializing narrative: where narrative theory and geography meet. Columbus: The Ohio State University Press, 2016.

SOJA, E. "History: geography: modernity". In: DURING, S. (ed.) The cultural studies reader. London: Routledge, 1993. p. 113-125.

\section{Referências audiovisuais}

AQUARIUS. Kleber Mendonça Filho, Brasil, 2016.

O SOM ao redor. Kleber Mendonça Filho, Brasil, 2013.

RECIFE frio. Kleber Mendonça Filho, Brasil, 2009.

submetido em: 13 ago. 2018 | aprovado em 27 mai. 2019 